\title{
ƯNG DỤNG CÔNG NGHỆ VIẼ̃N THÁM VÀ GIS THÀNH LẬP BẢN ĐỒ THẢM THỬC VẠTT VÀ BƯỚC ĐẦU ƯỚC TÍNH KHẢ NĂNG TÍCH TỤ CARBON Ở VỪ̛̀ QUỐC GIA YOK DON
}

\author{
ThS. MAC VĂN CHIÉN ${ }^{(1)}$, PGS.TS. TRÂN VĂN Ý(2), \\ ThS. NGUYẼ̃N THANH TUÂN ${ }^{(2)}$, TS. LƯU THẾ ANH(3), ThS. ĐINH TH! THU HIÊN ${ }^{(4)}$ \\ ${ }^{(1)}$ Công ty CP CAVICO Xây dựng Nhân lực và dịch vụ \\ (2)Bảo tàng Thiên nhiên Việt Nam - Viện Hàn Lâm Khoa học và Công nghệ Việt Nam \\ ${ }^{(3)}$ Viện Địa lý - Viện Hàn Lâm Khoa học và Công nghệ Việt Nam \\ ${ }^{(4)}$ Viện Khoa học Công nghệ Cơ khí, Tự động hóa và Môi trường
}

\section{Tóm tắt:}

Tư liệu ảnh viễn thám và công nghệ hệ thông tin địa lý (GIS) đã và đang được sử dụng hiệu quả trong công tác đánh giá hiện trạng và theo dõi biến động của lớp phủ thực vật, giúp khắc phục được các nhược điểm của các phương pháp điều tra truyền thống trong lâm nghiệp. Nghiên cứu này trình bày tóm tắt kết quả thành lập bản đồ thảm thực vật VQG Yok Don tỷ lệ 1:50.000 từ ảnh SPOT5 chụp tháng 1/2011, trong đó rừng lá rộng thường xanh giàu có 4.145,76 ha; rừng lá rộng thường xanh trung bình có 16.928,97 ha; rừng khộp có 84.595, 43 ha và rừng lá rộng nửa rụng lá nghèo có 8.216,88 ha. Kết hợp với số liệu điều tra sinh khối bề mặt của các kiểu rừng này, nghiên cứu đã ước tính nhanh trữ lượng carbon tích lũy trong từng kiểu rừng và trên toàn bộ lâm phần của VQG Yok Don khoảng 5.861.237,48 tấn. Đây là cơ sở khoa học ban đầu giúp lượng giá giá trị kinh tế của môi trường rừng VQG Yok Don thông qua tham gia thị trường carbon.

\section{Mỏ đầu}

Ngày nay, nhờ có những thành tựu vượt bậc của công nghệ vũ trụ, các tư liệu ảnh viễn thám và hệ thông tin địa lý (GIS) được ứng dụng hiệu quả trong công tác giám sát và đánh giá biến động bề mặt Trái đất, quản lý các nguồn tài nguyên thiên nhiên, bảo vệ môi trường, phòng tránh và giảm nhẹ thiên tai. Từ các nguồn tư liệu ảnh viễn thám đa thời gian và đa độ phân giải, có thể phân tích và giải đoán để đánh giá hiện trạng cũng như biến động lớp phủ mặt đất theo thời gian và không gian. Qua đó, hoàn toàn có thể tính toán được sinh khối của rừng, từ đó quy đổi ra lượng carbon tích tụ cũng như năng lực hấp thụ $\mathrm{CO}_{2}$ của lâm phần. Phát triển các phương pháp tính toán và lượng hóa khả năng tích lũy carbon của các kiểu thảm thực vật rừng là một trong các mục tiêu quan trọng của Chương trình "Giảm thiểu khí phát thải từ suy thoái và mất rừng (REED)" ở Việt Nam hiện nay, từ đó xác định đường carbon cơ sở của từng kiểu rừng, làm căn cứ khoa học để chứng minh được lượng carbon thu nap được bởi các thảm rừng. Ủy ban liên quốc gia về biến đổi khí hậu (IPCC) đã chấp nhận sự tham gia và thúc đẩy các nước phát triển thực hiện mục tiêu cắt giảm phát thải khí nhà kính bằng cách mua các tín dụng carbon của các nước đang phát triển từ những khu rừng hấp thụ $\mathrm{CO}_{2}$. Tuy nhiên, việc áp dụng các phương pháp định lượng khả năng hấp thụ carbon của rừng tự nhiên nhiệt đới rất khó và tốn kém, đặc biệt trong điều kiện Việt Nam. Do vậy, ước lượng một cách tương đối lượng carbon tích lũy của các lâm phần bằng phương pháp đánh giá nhanh, ít tốn kém là rất cần thiết và có ý nghĩa trong điều 
kiện hiện tại.

Vườn Quốc gia (VQG) Yok Don nằm trên địa bàn hai tỉnh Đắk Lắk và Đắk Nông, có diện tích là 115.545 ha [3]. Đây là VQG có diện tích lớn nhất cả nước, độ che phủ của rừng tự nhiên rất cao, chủ yếu là hệ sinh thái rừng khộp rộng lớn và mang tính đặc trưng của rừng nhiệt đới Đông Nam Á [4]. Đến nay, tài nguyên rừng của VQG Yok Don đã có nhiều thay đổi, công tác phúc tra rừng, cập nhật bản đồ thảm thực vật trên cơ sở giải đoán ảnh vệ tinh và ước tính khả năng tích tụ carbon là hết sức cần thiết, làm cơ sở ban đầu xác định giá trị môi trường rừng của VQG thông qua thị trường carbon. Bài báo này giới thiệu kết quả ứng dụng tư liệu ảnh vệ tinh SPOT5 và công nghệ GIS để thành lập bản đồ thảm thực vật và khả năng tích tụ carbon của VQG Yok Don.

\section{Dữ liệu và phương pháp nghiên cứu}

\subsection{Dư liệu sử dụng}

- Ảnh vệ tinh SPOT5 với 3 kênh đa phổ độ phân giải $10 \mathrm{~m}$ do Trung tâm Thu nhận và Xử lý ảnh Viễn thám (Cục Viễn thám Quốc gia) chụp và xử lý tháng 01/2011.

- Kết quả điều tra thành phần loài, sinh khối ở 20 ô tiêu chuẩn (OTC) đại diện cho các kiểu rừng ở VQG Yok Don năm 2012 của đề tài "Nghiên cứu đánh giá, phân loại thảm thực vật rừng dễ cháy và đề xuất các giải pháp kiểm soát cháy rừng và giảm thiểu ô nhiễm khói mù tỉnh Đắk Lắk" do Viện Địa lý chủ trì thực hiện từ năm 2012 - 2013 [1].

- Bản đồ nền địa hình tỷ lệ 1:50.000 và kết quả điều tra các hệ sinh thái rừng thuộc Dự án "Quy hoạch bảo tồn và phát triển bền vững Vườn Quốc gia Yok Don giai đoạn 2010 - 2020" do Liên danh Viện Sinh thái và Tài nguyên Sinh vật - Viện Địa lý - Viện Khoa học Thủy lợi thực hiện [4].

\subsection{Phương pháp nghiên cứu}

- Phương pháp điều tra ô tiêu chuẩn: Dùng thước dây xác lập 20 OTC, mỗi ô có diên tích $500 \mathrm{~m}^{2}(25 \mathrm{~m} \times 20 \mathrm{~m})$ trong các kiểu rừng cần điều tra. Dùng máy định vị GPS để xác định tọa độ các góc của OTC. Tiến hành lập 4 ô dạng bản có diện tích $4 \mathrm{~m}^{2}$ (kích thước $2 \mathrm{~m} \times 2 \mathrm{~m}$ ) ở 4 góc của mối OTC để điều tra khối lượng vật liệu khô và tươi dưới tán rừng. Dùng thước đo đường kính ở vị trí $1,3 \mathrm{~m}\left(\mathrm{D}_{1,3 \mathrm{~m}}\right)$ của tất cả những cây có $\mathrm{D}_{1,3 \mathrm{~m}}$ $\geq 6 \mathrm{~cm}$ để tính đường kính (D) bình quân và tổng tiết diện ngang trung bình trên mỗi ha ( $\Sigma \mathrm{G} / \mathrm{ha})$. Đo chiều cao vút ngọn $\left(\mathrm{H}_{\mathrm{vn}}\right)$ ở tất cả các cấp đường kính để tính chiều cao $(\mathrm{H})$ bình quân mỗi ha và toàn bộ lâm phần. Xác định tên của tất cả các cây trên để tính tổ thành loài cây cho lâm phần và mật độ cây trên ha.

- Phương pháp giải đoán ảnh vệ tinh: Sử dụng phương pháp phân loại có kiểm định (Supervised Classification). Đây là phương pháp phân loại dựa trên 1 tập hợp các pixel mẫu (ROI) đã được chọn trước. Dựa vào tập hợp các mẫu này để xác định các pixel có cùng một số đặc trưng về phổ, từ đó phân loại chúng trên toàn bộ ảnh vệ tinh. Sử dụng thuật toán phân loại hàm xác suất cực đại (Maximum Likelihood Classification) để tiến hành phân loại những vùng mẫu đã chọn bằng phần mềm ENVI. Sau khi đã phân loại, tiến hành kiểm tra, đánh giá độ chính xác và xuất kết quả sang phần mềm Maplnfo để biên tập và trình bày bản đồ thảm thực vật VQG Yok Don.

- Phương pháp tính lượng carbon tích tụ: Sử dụng phương trình tương quan giữa hai đại lượng đường kính thân cây ở độ cao ngang ngực $1,3 \mathrm{~m}$ (D) và chiều cao của cây (H) do Bhishma (2010) đưa ra áp dụng cho vùng Châu Á [5]:

$$
A G B=0,0396 \times D^{2} \times H^{0,932}
$$

Trong đó, $A G B$ là sinh khối trên mặt đất (tấn/ha); $D$ là đường kính thân cây tại độ cao $1,3 \mathrm{~m} ; \mathrm{H}$ là chiều cao thân cây; 0,0396 
và 0,932 là các hệ số chuyển đổi.

Hàm lượng carbon (CBS) tích tụ trong sinh khối của lâm phần (đơn vị tính: tấn C/ha)) được xác định thông qua việc áp dụng hệ số mặc định 0,5 thừa nhận bởi Ủy ban Liên chính phủ về Biến đổi khí hậu IPCC (2003) [6]. Nghĩa là hàm lượng các bon được tính bằng cách nhân sinh khối khô với 0,5.

$$
\mathrm{CBS}=0,5 \times \mathrm{AGB}
$$

\section{Kết quả và thảo luận}

\subsection{Hệ thống phân loại thảm thực vật VQG Yok Don}

Áp dụng tiêu chí và hệ thống phân loại rừng dựa vào loài cây và trữ lượng của Bộ Nông nghiệp và Phát triển nông thôn ban hành (2009) [2] và kết hợp với kết quả điều tra các hệ sinh thái rừng của Viện Sinh thái và Tài nguyên Sinh vật - Viện Địa lý (2011), các tác giả đã lựa chọn được hệ thống phân loại phục vụ thành lập bản đồ thảm thực vật VQG Yok Don từ ảnh vệ tinh SPOT5 chụp năm 2011 như sau: (Xem bảng 1)

\subsection{Xây dựng chìa khóa giải đoán}

Chìa khóa giải đoán là chỉ tiêu để phân biệt đối tượng, được thiết lập dựa vào cấp độ xám của ảnh, kinh nghiệm và kiến thức của người giải đoán, ảnh thực địa được chụp bằng máy camera có gắn GPS định vị tọa độ trong đợt thực địa điều tra các OTC vào tháng 1 năm 2012. Các yếu tố giải đoán như: màu sắc, kích thước, hình dạng, kiến trúc, vị trí và mối quan hệ với các đối tượng xung quanh, kết hợp với thời gian chụp để xây dựng chìa khóa giải đoán. (Xem bảng 2)

\subsection{Xây dựng bản đồ thảm thực vật VQG Yok Don}

Kết quả thành lập bản đồ thảm thực vật VQG Yok Don ở tỷ lệ 1:50.000 từ tư liệu ảnh vệ tinh SPOT5 năm 2011 được trình bày khái quát trong Hình 1 và quy mô diện tích

Bảng 1: Hệ thống phân loại thảm thực vật VQG Yok Don

\begin{tabular}{|c|c|c|}
\hline Nhóm & Loại thảm thụ̣c vật & Khái niệm \\
\hline \multirow{4}{*}{$\begin{array}{l}\text { Lớp phủ } \\
\text { rừng }\end{array}$} & Rừng lá rộng thường xanh giàu & $\begin{array}{l}\text { Là rừng gỗ có cây lá rộng xanh quanh năm và } \\
\text { uchiếm trên } 75 \% \text { số cây. Rừng có trữ lượng } 201 \text { - } \\
300 \mathrm{~m}^{3} / \mathrm{ha}\end{array}$ \\
\hline & $\begin{array}{l}\text { Rừng lá rộng thường xanh trung } \\
\text { bình }\end{array}$ & $\begin{array}{l}\text { gà rừng gỗ có cây lá rộng xanh quanh năm và } \\
\text { chiếm trên } 75 \% \text { số cây. Rừng có trữ lượng } 101 \text { - } \\
200 \mathrm{~m}^{3} / \mathrm{ha}\end{array}$ \\
\hline & $\begin{array}{l}\text { Rừng khộp (rừng lá rộng rụng lá } \\
\text { theo mùa) }\end{array}$ & $\begin{array}{l}\text { á Là rừng có các loài cây rụng lá theo mùa chiếm } \\
75 \% \text { số cây trở lên. Rừng có trữ lượng } 50-100 \\
\mathrm{~m}^{3} / \text { ha }\end{array}$ \\
\hline & Rừng lá rộng nửa rụng lá nghèo & $\begin{array}{l}\text { Là rừng có các loài cây thường xanh và cây rụng } \\
\text { olá theo mùa với tỷ lệ hốn giao theo số cây mỗi loại } \\
\text { từ } 25 \% \text { đến } 75 \% \text {. Rừng có trữ lượng dưới } 50 \mathrm{~m}^{3} / \mathrm{ha}\end{array}$ \\
\hline $\begin{array}{l}\text { Đối tượng } \\
\text { khác }\end{array}$ & & $\begin{array}{l}\text { Là vùng có dưới } 1 / 3 \text { diện tích được bao phủ bởi } \\
\text { thực vật, gồm đất nông nghiệp, đất bỏ hoang, đất } \\
\text { ở, đất giao thông, thủy lợi... }\end{array}$ \\
\hline Mặt nước & & $\begin{array}{l}\text { Là các vùng bị nước bao phủ quanh năm: Sông } \\
\text { suối, hồ đập }\end{array}$ \\
\hline
\end{tabular}


Bảng 2: Chìa khóa giải đoán ảnh vệ tinh VQG Yok Don

\begin{tabular}{|c|c|c|c|}
\hline Tên lớp phủ & Mẫu ảnh & Dấu hiệu nhận biết & Ảnh thực địa \\
\hline $\begin{array}{l}\text { Rừng lá rộng thường } \\
\text { xanh giàu }\end{array}$ & & $\begin{array}{l}\text { Màu đỏ thẫm, hình dạng } \\
\text { không xác định, cấu trúc } \\
\text { tương đối mịn }\end{array}$ & (2) \\
\hline $\begin{array}{l}\text { Rừng lá rô̂ng thường } \\
\text { xanh trung bình }\end{array}$ & & $\begin{array}{c}\text { Màu đỏ nhạt, hình dạng } \\
\text { không xác định, cấu trúc } \\
\text { hạt thô, lốm đốm }\end{array}$ & \\
\hline Rừng khộp & & $\begin{array}{c}\text { Màu đỏ nhạt-tím, hình } \\
\text { dạng không xác định, cấu } \\
\text { trúc lốm đốm }\end{array}$ & \\
\hline $\begin{array}{l}\text { Rừng lá rộng nửa rụng } \\
\text { lá nghèo }\end{array}$ & & $\begin{array}{l}\text { Màu vàng nhạt, hình dạng } \\
\text { không xác định, cấu trúc } \\
\text { lốm đốm }\end{array}$ & \\
\hline Đối tượng khác & & $\begin{array}{c}\text { Màu xanh-trắng, hình } \\
\text { dạng không xác định, cấu } \\
\text { trúc lốm đốm }\end{array}$ & \\
\hline Mặt nướcc & & \begin{tabular}{|} 
Màu xanh xẫm hoắc màu \\
đen có dạng tuyến, cấu \\
trúc lốm đốm
\end{tabular} & \\
\hline
\end{tabular}

của từng kiểu thảm phủ được thống kê trong Bảng 3.

Kết quả thống kê trên bản đồ cho thấy, rừng khộp có diện tích lớn nhất khoảng $84.595,43$ ha (chiếm $73,27 \%$ diện tích tự nhiên của Vườn), phân bố rộng khắp trên lãnh thổ của Vườn; tiếp đến là rừng lá rộng thường xanh trung bình có diện tích 16.928,97 ha (chiếm 14,66\%); rừng lá rộng nửa rụng lá nghèo có diện tích $8.216,88$ ha (chiếm 7,12\%); rừng lá rộng thường xanh giàu có diện tích nhỏ nhất khoảng 4.145,76 ha (chiếm 3,59\%).

Ngoài ra, diện tích đất nông nghiệp, đất giao thông, đất xây dựng, đất sau nương rẫy của Vườn có khoảng 677,93 ha (chiếm $0,59 \%$ ); diện tích đất mặt nước khoảng 889,03 ha (chiếm 0,77\%), gồm các hồ thủy lợi, sông Srêpôk và hệ thống các phụ lưu (suối Đắk Ken, Đắk Lau, Đắk Tol,...). 
Bảng 3: Diện tích các loại thảm thực vật VQG Yok Don

\begin{tabular}{|c|l|r|r|}
\hline STT & \multicolumn{1}{|c|}{ Loại rừng } & \multicolumn{1}{c|}{ Diện tích (ha) } & \multicolumn{1}{c|}{ Tỷ lệ (\%) } \\
\hline 1 & Rừng lá rộng thường xanh giàu & $4.145,76$ & 3,59 \\
\hline 2 & Rừng lá rộng thường xanh trung bình & $16.928,97$ & 14,66 \\
\hline 3 & Rừng khộp & $84.595,43$ & 73,27 \\
\hline 4 & Rừng lá rộng nửa rụng lá nghèo & $8.216,88$ & 7,12 \\
\hline 5 & Đối tượng khác & 677,93 & 0,59 \\
\hline 6 & Mặt nước & 889,03 & 0,77 \\
\hline & Tổng cộng & $\mathbf{1 1 5 . 4 5 4 , 0 0}$ & $\mathbf{1 0 0}$ \\
\hline
\end{tabular}

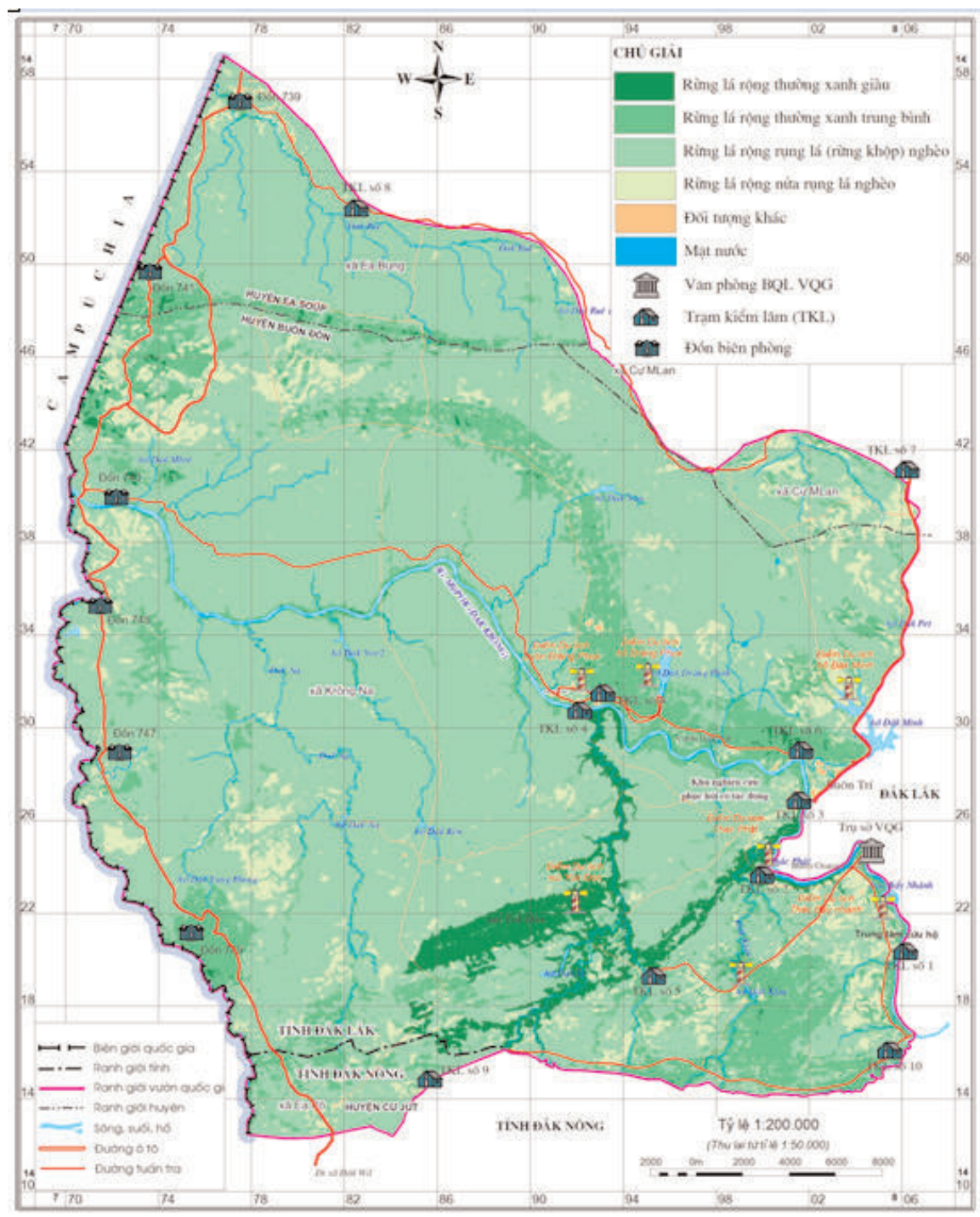

Hình 1: Bản đồ thảm thực vật QG Yok Don năm 2011 


\section{Don \\ 3.4. Ước tính sinh khối và khả năng tích tụ carbon của các kiểu rừng VQG Yok}

Kết quả ước tính sinh khối bề mặt VQG Yok Don cho thấy, tổng sinh khối bề mặt toàn lâm phần của Vườn năm 2011 vào khoảng 11.722.475,02 tấn. Trong đó, sinh khối bề mặt của rừng khộp là lớn nhất, khoảng 7.522.548,10 tấn (trung bình: 88,92 tấn/ha); tiếp đến sinh khối của rừng lá rộng thường xanh trung bình khoảng 2.844.259,60 (trung bình: 168,01 tấn/ha); rừng lá rộng thường xanh nghèo khoảng 1.135.285,35 tấn (trung bình: 273,84 tấn/ha) và rừng lá rộng rụng lá nghèo khoảng 220.381,97 (trung bình: 26,82 tấn/ha) (Bảng 4). Tổng lượng carbon tích lũy trong toàn bộ lâm phần của VQG Yok Don ước tính khoảng 5.861.237,48 tấn, cụ thể đối với từng kiểu rừng như sau:

- Đối với rừng lá rộng thường xanh giàu, lượng carbon tích lũy lớn nhất, trung bình khoảng 136,92 tấn C/ha và toàn lâm phần của kiểu rừng này là 567.642,61 tấn.

- Rừng lá rộng thường xanh trung bình có lượng carbon tích lũy là 84,01 tấn C/ha và toàn lâm phần của kiểu rừng này là 1.422.129,89 tấn.

- Rừng khộp có lượng carbon tích lũy toàn lâm phần là lớn nhất (3.761.273,99 tấn) vì kiểu rừng này có diện tích chiếm tới $73,27 \%$ diện tích tự nhiên của Vườn, mặc dù lượng carbon tích lũy trung bình trên mỗi ha không phải là cao (khoảng 44,46 tấn C/ha).

- Rừng lá rộng nửa rụng lá có lượng carbon tích tụ là thấp nhất, trung bình khoảng 13,41 tấn C/ha và toàn lâm phần khoảng 110.190,99 tấn. (Xem bảng 4, hình 2)

\section{Kết luận}

Sử dụng tư liệu ảnh viễn thám và công nghệ GIS thành lập bản đồ hiện trạng lớp phủ thực vật có nhiều ưu điểm vượt trội so với phương pháp điều tra lâm nghiệp truyền thống như: cập nhật nhanh thông tin về hiện trạng lớp phủ thực vật, qua đó giúp tiết kiệm được thời gian và kinh phí thực hiện. Đồng thời, kết quả phản ánh trung thực hiện trạng lớp phủ thực vật của khu vực nghiên cứu ở từng thời điểm cụ thể. Đối với các Vườn quốc gia và khu bảo tồn thiên nhiên có diện tích không lớn, việc sử dụng các tư liệu ảnh viễn thám đa thời gian có độ phân giải cao (như ảnh SPOT) trong việc đánh giá hiện trạng và theo dõi biến động của thảm thực vật sẽ mang lại hiệu quả cao.

Từ kết quả giải đoán thảm thực vật Vườn Quốc gia Yok Don từ ảnh vệ tinh SPOT5 chụp tháng 1/2011 kết hợp với số liệu điều tra sinh khối bằng các ô tiêu chuẩn cho phép ước tính nhanh sinh khối trên toàn bộ lâm phần của Vườn. Từ đó quy đổi để ước lượng được trữ lượng carbon tích tụ trong từng kiểu thảm thực vật rừng cũng như trên toàn lâm phân. Đây sẽ là cơ sở ban đầu giúp lượng hóa giá trị kinh tế của môi trường rừng ở VQG Yok Don thông qua tham gia thị trường carbon.

Tuy nhiên, để có số liệu chính xác hơn về trữ lượng carbon tích tụ trong lâm phần của VQG Yok Don, cần thiết phải tiếp tục nghiên cứu, điều tra và tính toán sinh khối cho từng bộ phận rễ, thân, cành và lá của từng trạng thái rừng khác nhau. $O$

\section{Tài liệu tham khảo}

[1]. Lưu Thế Anh, 2014. Nghiên cứu đánh giá, phân loại thảm thực vật rừng dễ cháy và đề xuất các giải pháp kiểm soát cháy rừng và giảm thiểu ô nhiễm khói mù tỉnh Đắk Lắk. Báo cáo tổng kết đề tài Cấp Viện Hàn lâm Khoa học và Công nghệ Việt Nam, mã số 
Bảng 4: Sinh khối bề mặt và lượng carbon tích tụ trung bình trên 1 ha và toàn bộ lâm phần của VQG Yok Don năm 2011

\begin{tabular}{|c|l|c|c|c|c|}
\hline \multirow{2}{*}{ Loại rừng } & \multicolumn{2}{c|}{ Sinh khối bề mặt (tấn) } & \multicolumn{2}{c|}{ Lượng carbon tích tụ (tấn) } \\
\cline { 3 - 6 } & & Trên 1ha & Toàn lâm phần & Trên 1ha & Toàn lâm phần \\
\hline 1 & Rừng lá rộng thường xanh giàu & 273,84 & $1.135 .285,35$ & 136,92 & $567.642,61$ \\
\hline 2 & Rừng lá rộng thường xanh trung bình & 168,01 & $2.844 .259,60$ & 84,01 & $1.422 .129,89$ \\
\hline 3 & Rừng khô rụng lá (Rừng khộp) & 88,92 & $7.522 .548,10$ & 44,46 & $3.761 .273,99$ \\
\hline 4 & Rừng lá rộng nửa rụng lá nghèo & 26,82 & $220.381,97$ & 13,41 & $110.190,99$ \\
\hline & Tổng cộng & & $\mathbf{1 1 . 7 2 2 . 4 7 5 , 0 2}$ & & $\mathbf{5 . 8 6 1 . 2 3 7 , 4 8}$ \\
\hline
\end{tabular}

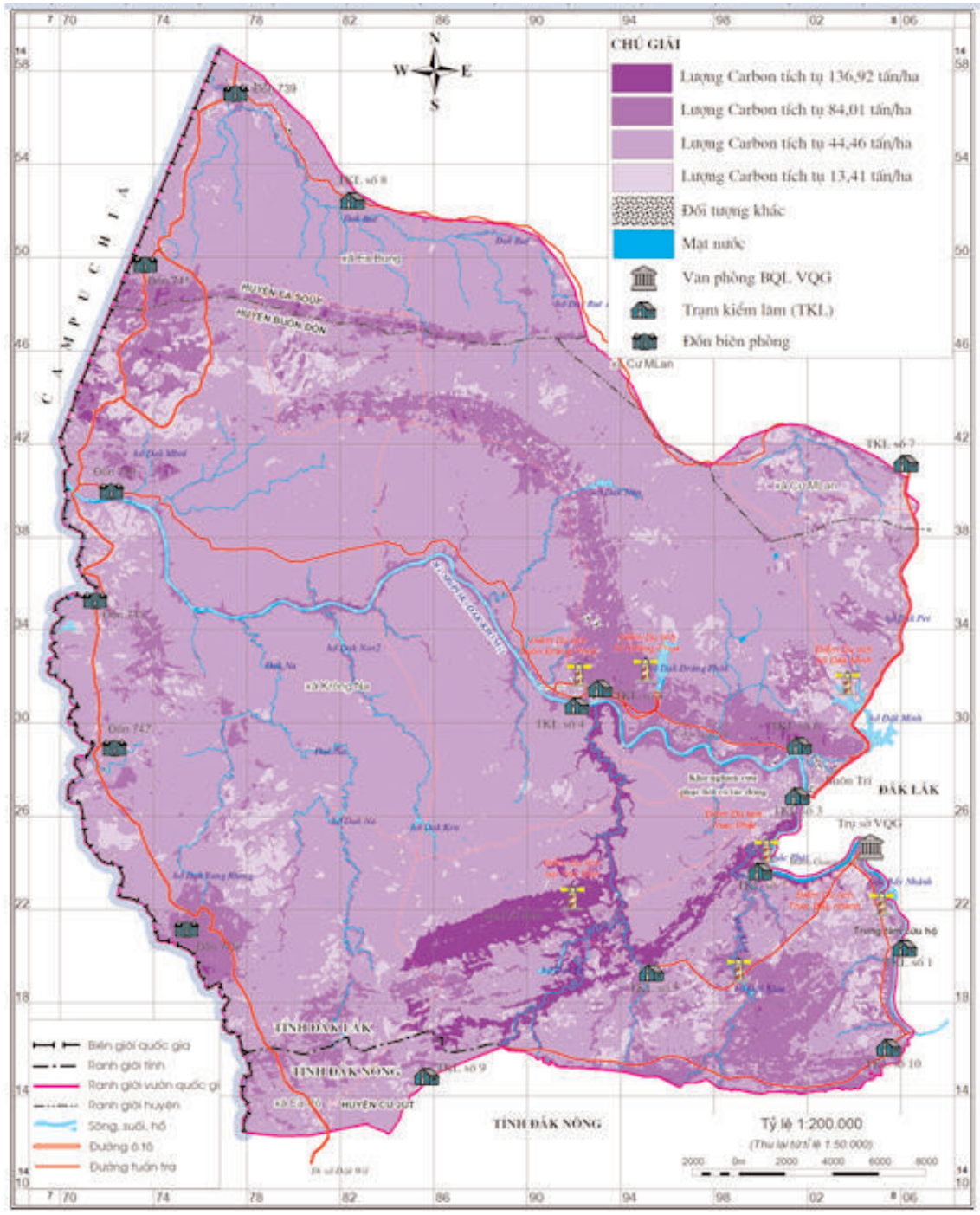

Hình 2: Bản đồ ước tính lượng carbon tích tụ ở VQG Yok Don 
VAST05.02/12-13. Tài liệu lưu trữ tại Viện Địa lý, Hà Nội.

[2]. Bộ Nông nghiệp và Phát triển nông thôn, 2009. Thông tư số 34/2009/TT-BNNPTNT Quy định tiêu chí xác định và phân loại rừng.

[3]. Thủ tướng Chính phủ, 2002. Quyết định số 39/2002/QĐ-TTg ngày 18/3/2002 về việc mở rộng Vườn Quốc gia Yok Don tỉnh Đắk Lắk.

[4]. Viện Sinh thái và Tài nguyên Sinh vật, Viện Địa lý và Viện Quy hoạch Thủy lợi, 2011. Quy hoạch bảo tồn và phát triển bền vững Vườn Quốc gia Yok Don giai đoạn 2010 - 2020.

[5]. Bhishma, P., et al 2010. Forest carbon stock measurement: Guidelines for measuring carbon stocks in community-managed forests. Asia Network for Sustainable Agriculture and Bioresources, Federation of Community Forest Users and International Centre for Integrated Mountain Development, Nepal.

[6]. Intergovernmental Panel on Climate Change, 2003. Good Practice Guidance for Land Use, Land Use Change and Forestry. IPCC/IGES, Hayama, Japan. $O$

\section{Summary}

Application of Remote Sensing and Geographical Information System in vegetation cover mapping and initial establishment of accumulation carbon in Yok Don National Park

MSc. Mac Van Chien, Cavico Constrution Manpower and Services Joint Stock Company

Assoc. Prof. Dr. Tran Van Y, MSc. Nguyen Thanh Tuan, Vietnam National Museum of Nature - Vietnam Academy of Science and Technology

Dr. Luu The Anh, Institute of Geography - Vietnam Academy of Science and Technology

MSc. Dinh Thi Thu Hien, Institute for Mechanical, Automation and Environmental Science and Technologies

Remotely sensed image and Geographical Information Systems (GIS) technology has been used effectively in the evaluation of current vegetation cover status and in monitoring of vegetation cover change. This approach helds to overcome the disadvantages of the traditional methods of investigation in forestry. This study presents a summary of the results of vegetation cover mapping in Yok Don National Park at scale of 1:50,000 by using SPOT5 image captured in January 2011, in which the rich evergreen broadleaf forest has 4145.76 ha; average evergreen broadleaf forest has 16928.97 ha; dipterocarp forest has 84595.43 ha of and poor semi-deciduous broadleaf forest covers 8216.88 ha. In combination with survey data of the surface biomass of these forest types, the stock of accumulation carbon in each forest types was estimated. The total of carbon stock of Yok Don National Park is $5,861,237.48$ tons. This is the original scientific basis for estimating the economic value of the forest environment of Yok Don National Park through participation in the carbon market. $\bigcirc$

Ngày nhận bài: 09/6/2014. 